\title{
Enhancing Learners' Oral Fluency in Using English Through TBLT Approach at the Universitas Negeri Padang
}

\author{
La Mai Tulum ${ }^{1 *}$ and Havid Ardi ${ }^{2}$
}

\author{
${ }^{1}$ English Department, FBS Universitas Negeri Padang, Padang, Sumatra Barat 25131, Indonesia \\ ${ }^{2}$ English Department, FBS Universitas Negeri Padang, Padang, Sumatra Barat 25131, Indonesia \\ *Corresponding author email: lamaitulum91@gmail.com
}

\begin{abstract}
Task-based Language Teaching Approach (TBLT) has been introduced in the Asian language Classroom for a couple of decades [1] due to its effectiveness of learners' language development but when it comes to implementing and research of TBLT in higher education language classroom, little attention has been paid as a result, learners' English language proficiency in particular in the aspect of oral fluency is limited. Therefore, this research aimed to fill the gap to enhance learners' oral fluency through the TBLT approach at the higher education level with classroom-based action research. The results discovered that learners' oral fluency has developed slightly during the period of the TBLT approach in the classroom. Oral fluency was assessed in the format of the IELTS Speaking test with the trained IELTS examiner as an inter-rater and researcher himself and therefore learners were scored on the scale of IELTS band descriptors. Data were analyzed with Heaton formula and interview for descriptive purposes and employed Wilcoxon Sign-rank test for the quantitative analysis.
\end{abstract}

Keywords: TBLT, Oral fluency, higher education

\section{INTRODUCTION}

Being able to speak fluently in a foreign language journey is the dream of the English as a second or foreign language learner and therefore, language teaching approaches have been transforming from grammar-translation method to the embracing communicative ones in Asian language classrooms[2] and there are increasing demands to address developing communication skills in English in East Asia[3]. However, the majority of the English learners are struggling with their oral fluency despite having a good knowledge of other aspects of the English language. In particular, in the Indonesian context, students of higher education levels are still struggling with basic communication skills even though they have been learning English for a decade as a compulsory subject [4] by the time they get into tertiary education. Most of the Southeast Asian English language classrooms seem to be grammar-oriented and examoriented as opposed to focusing on the developing learners' communicative abilities as a result, students were hindered in their development of adequate fluency[5]. It is said that most Asian English language classrooms seemed to be teacher-dominated, text-book directed and memorization-based [1]. Taking account of the Indonesian higher education situation in which learners do not have much exposure to English and have little need to communicate and use it in their daily lives. All academic fairs concerning writing thesis for master programs, bachelor programs, and even in doctoral programs are only written in their first language which is Bahasa Indonesia apart from students of the English department. Moreover, language instruction is also only in learners' first language, and therefore, the use of the English language is extremely limited at the higher education level of Indonesia.

Besides that, regarding English language exposure, there are only two earlier semesters which is equivalent to eight months for four years bachelor program and therefore, English language exposure seems to be very limited as a result, learners' oral fluency suffers. It is time to reconsider students' English language proficiency at the higher education level of Indonesia. However, this study focused on students from the University of Indonesia which is Universitas Negeri Padang from different faculties.

This study focused on enhancing learners' oral fluency in using English through the TBLT approach at the higher education level. Even though learners have little need to communicate in English outside of their 
classroom, at least, learners' communicative ability has been enhanced with pair works and group works activities through the TBLT approach in the classroom. Therefore, the implementation of the TBLT approach at the higher education level should be applied throughout their academic studies so that they will be fully equipped concerning English language communication skills for further studies as well as for their related fields in the future.

The study aims to discover the following research question: "How does the TBLT approach enhance oral fluency skills through classroom action research at the students of Universitas Negeri Padang, Indonesia?"

\section{LITERATURE REVIEW \\ 2.1 What is TBLT?}

TBLT stands for Task-Based Language Teaching and basically, its' approach is designed the tasks which reflect learners' real-world situation and their daily lives. There are many definitions of TBLT but focusing on a task is all has in the common and pivotal role of its approach [6]. According to [7] the TBLT approach has some benefits namely; (1) it is usually based on learners' needs and interests (2) it prioritizes learners' communicative ability through peers interaction (3) it reflects on learners' real-world situations. (4) Learners are given more opportunities to develop language skills as well as through the learning process. (5) It promotes learners' self-development through classroom environment and (6) it provides authentic language use that learners are likely to encounter and use outside of the classroom. By looking at these benefits of using the TBLT approach in the classroom, learners are given more opportunities to strengthen their communicative competence through being exposed to authentic texts and connected to the real-world situation as the main objective of the TBLT approach prioritizes learners' communicative competencies [8]. In addition to that, learners are taught not only the language but also the soft skills through the learning process. In other words, learners are learning teamwork skills in the language classroom through collaborative tasks and develop their critical thinking which is a pivotal role for the $21 \mathrm{st}$ century of education at the same time. The basic concept of approaching TBLT in the language classroom is developing learners' confidence and general oral fluency in using English without focusing only on linguistic competence [9].

According to the Ellis (2003), TBLT emphasizes the importance of engaging learners' natural abilities for acquiring language incidentally as they engage with language as a meaning-making tool and thus contrasts with structural approaches that emphasize language as an object to be systematically taught and intentionally learned. Therefore, TBLT is beyond teaching the language but also fostering learners' creative skills due to the fact that learners are usually given problems to solve and create or organize the event through pairs or group works during the learning process. By providing these activities, learners are given a lot of opportunities to practise their English with their peers during the learning process as a result, enhance their oral fluency skills while developing their soft skills at the same time. Moreover, some believe that TBLT would not be suitable for a complete beginner, young learners and exam preparations classes but it is perfectly suitable if we design depends on the learners and scaffolds accordingly.[10][11].

\subsection{What is a task?}

While implementing TBLT approach and applying in the classroom, there is a big question in relation to the tasks among the educators. It is said that there are many challenges when TBLT approach is implemented in an Asian context [12].The question is "What is a task?" or "What does a task really mean?". As most educators are bewildered what a task actually is and interpret in a different way and understandings of TBLT[13] [14]According to Ellis (2003), a task can be defined as follow:

1. A task is a work plan.

2. A task involves a primary focus on meaning.

3. A task involves real-world processes of language use.

4. A task can involve any of the four language skills.

5. A task engages the cognitive process.

6. A task has a clearly defined communicative outcome.

Moreover, according to [11] if the activities or tasks can be called "yes" in the following questions, then tasks or activities likely to be called a task such as will the activity engage learners' interest?, Is there a primary focus on meaning?, Is there a goal or an outcome?, Is success judged in terms of outcome?, Is completion a priority? And does the activity relate to real world activities? By looking at these widely known authors' definitions, a task can be called something that engages learners' interest while learning process is going on and there is an outcome at the end of the activity. In other words, learners knows there will be some solutions or outcomes at the end of the activity so it gives a sense of achievement and motivations to move forward and stimulates their curiosity can even lead to a better attitudes towards learning English. Therefore, selecting the tasks appropriately to suit the learners' interest and engagement is the focal point of the 
teacher's role of TBLT approach and can adapt the materials depends on the learners' interest as there is no a single method of TBLT approach [15].

\subsection{Why TBLT?}

The reason why TBLT should be applied not only in the elementary or secondary education but also in the tertiary education is because it promotes communicative competence and fluency in the first place but very limited research has been conducted in the Indonesian tertiary context even though TBLT has been widely used and promoted in Asia [16] and this study attempts to fill a gap in this regard.

One of the reasons is that applying TBLT approach in the English language classroom at the tertiary education could lead to learners' oral fluency development and as a whole could enhance learners' communicative competence ability. As[17] said TBLT prioritizes fluency as opposed to accuracy and therefore learners should be able to use the language with speed and confidence which can lead to sacrificing of accuracy. Moreover, Candlin (1987) claimed that an approach based on tasks would enable learners to become more aware of their own personalities and social roles, foster self-realization and self-fulfillment and enhance their self-confidence. By looking at this claim, TBLT is not merely teaching language or related subjects but it beyond the teaching language in the perspective of teaching English language. In fact, it fosters learners' collaborative skills and team work skills while learning English at the same time. This is one of the reasons why TBLT should implement in the tertiary education context in Indonesia.

Another thing to take into consideration of why TBLT should apply in the English language classroom is that [17]its aim prioritizes fluency as opposed to the accuracy but it does not mean neglecting the accuracy of the language. In particular, in Asian classroom, according to [17]"our students know the grammar but they can't use the language" which indicates that Asian language classroom basically focuses on the grammar or vocabulary oriented as opposed to focusing on communicative ability of the learners. When we look at the Korean context which is considered to be exambased society [8] as learners' success is based on the results of the examination. However, the world has changed and so do the education and therefore, learners' should be equipped with more hands-on experience and should be prepared for the real-world communication in the English language classroom. As Ur (2020) said that "It is vital for students using English in the 21 $1^{\text {st }}$ century to develop a critical approach to texts they encounter through the media. English teachers can help to support such as approach by fostering the development of higher order thinking skills in the course of learning tasks and their implementation in a critical approach to texts". As TBLT approach has been regarded as one of the effective methods to enhancing learners speaking ability (Kozawa, 2011) and help developing learners' autonomy (Willis \& Willis, 2011) and therefore, TBLT approach is well suited to foster learners' communicative competence at the higher education level.

\subsection{What is oral fluency?}

Defining oral fluency could be very difficult to have accurate information due to the fact that many well-known authors or writers defined in a different way. Among them, according to [18], fluency means having ability to express the idea clearly the way L1 does, the ability to speak in another language with little or no foreign accent and being able to use in a wide range of vocabulary and with few grammatical mistakes. There are three senses of fluency [18] namely cognitive fluency, utterance fluency and perceived fluency. Cognitive fluency refers to the speaker's ability to the mobilization whereas utterance fluency is considered to be features of utterance such as hesitation or pausing and the last perceived fluency is related to the inferences listeners make. According to Fillmore (1979), fluency refers to being able to talk at length with few pauses and fill time with talk (p.93). But according to Thornbury (2006), the features of fluency could be defined as follows: (1) pauses may be long but not frequent (2) pauses are usually filled (3) pauses occur at meaningful transition points and (4) there are long runs of syllables and words between pauses.

When we look at the Rehbein' (1987, p.104) fluency definition, "fluency" means that the activities of planning and uttering can be executed nearly simultaneously by the speaker of the language. In addition to that, Meisel $(1987$, p.86) claimed that fluency equals the communicative acceptability of the speech act, or "communicative fit" and expectations concerning this fit vary according to the situation.

It can be seen that fluency is defined in a variety way of concepts and therefore, [18] said that "Fluency remains such a complex phenomenon that no simple set of highly consistent measures will be found". Accessing oral fluency accurately can be quite vague and as no accurate oral fluency research has been done yet[18]. Therefore, in this study, the researcher refers to the criteria of IELTS speaking test format with some adaptations in scoring of learners' oral fluency.

\subsection{Why oral fluency is important?}

Being able to communicate effectively is basically based on someone's oral fluency skills as opposed to other skills. Some says that defining 
language proficiency is usually based on how someone can communicate orally in the first place. It demonstrates that how oral fluency is the crucial element in language learning.

As far as TBLT approach is concerned, its main priority is enhancing oral fluency as opposed to the accuracy[17]. Moreover, according to [17]there is something wrong with the way languages are taught in many classrooms and pointed out one of the problems is failing to acknowledge that language is much more than a grammatical system. That is one of the reason that most language learners know the grammar but unable to communicate in the real-world situation.

As this research is focusing on tertiary students and therefore, oral fluency is even more important as they are preparing for future studies or doing business and there is no doubt that there will have a lot of discussion and presentation in class or in their related workplaces and consult with their supervisors for the academic purposes or meeting with international clients for the workplace and therefore, tertiary education is the critical period of language learners to prepare communication skills for the future. However, even some students of English at the tertiary education sometimes present their final thesis in their own language which is Bahasa Indonesia due to oral fluency problems [4] and therefore, it is time to reconsider about the language use of tertiary students and teaching approaches at the English language classroom at higher education of Indonesia.

\subsection{How oral fluency is accessed?}

Generally speaking, some say that accessing oral fluency accurately is almost impossible as Lennon (1990) argued that "Fluency is an impression on the listener's part the psycholinguistic processes of speech planning and speech production are functioning easily and efficiently" (p.391). Moreover, [19], indeed, speed is one of the factors but this is not the only one to take into account to say being a fluent speaker as pausing and placement are also equally important to consider to access oral fluency. By looking at this claim, speed is as equally as important pausing naturally so that listeners could comprehend of the speakers' appropriate placement of pauses and intonation.

Having considered all factors of accessing oral fluency, this study employed IELTS speaking criteria but with some adaptations. That is to say, there are four criteria which are used in the IELTS speaking test namely, fluency and coherence, lexical resources, grammatical range and accuracy and pronunciation[20] but in this study, researcher employed only fluency criterion with some adaptations among others as the research of this study is developing learners' oral performance. Therefore, learners were examined with the trained IELTS examiner as an inter-rater as well as researcher so that learners were scored fairly in the aspect of oral fluency development over the research period.

\subsection{How does the IELTS speaking assessment look like?}

IELTS is known for its standardized test for university entrance exam for native English speaking countries for non-users of English those who want to enter and undertake undergraduate programs or post graduate programs. And therefore, it is recognized internationally for English language proficiency. Generally speaking, four skills are assessed in the IELTS test and speaking component is assessed individually with the trained examiner for about 11 to 14 minutes separately whereas other three modules are assessed at the same time and takes 2 hours and 40 minutes in total.

In this research, the researcher focuses on only speaking assessment of the IELTS test format. There are three parts of the test and part 1 is about casual topics which is related to the test taker's daily life and personal topics whereas part 2 is a monologue which is given specific topic by the examiner and the last part of the test is in-depth conversation or discussion related to the topic 2 and it is more abstract topic compared to the part 1 of the test.

The reason why IELTS speaking format is employed in order to assess learners' oral fluency in this study is that the test accesses learners' genuine communicative ability for the real-world situation or learners' are assessed through genuine conversation with a trained examiner which is related to their lives and therefore, assessment of learners' oral fluency through IELTS speaking format is matched perfectly with the TBLT approach because since TBLT approach is typically designed in order to reflect on the learners' real-world lives and engage in an authentic way to communicate with. As it is said, it is important to know for teachers how to access for the communicative competence and how to help learners through appropriate approach[21] not for accessing whether the students know the grammar but whether they can apply it in the real world of communication[17] and therefore, the researcher decided to employ IELTS speaking test format so that learners' in the aspect of oral fluency could improve during the research project.

\section{RESEARCH METHOD}

The research participants in the study were from the Students of Universitas Negeri Padang currently studying in a variety of faculty namely, Islamic studies, 
Economy, Early childhood education, psychology, and biology. Students were at different semesters at the time of the study ranging from semester 5 to 7 which is equivalent to the third year and final years of bachelor programs.

Regarding the level of learners' English proficiency at the beginning of the research, some of them were at $\mathrm{A} 1$ and $\mathrm{A} 2$ and most of them were at $\mathrm{B} 1$ level according to the CEFR (Common European Framework References) and therefore, the research study was conducted in a mixed ability class. In fact, before conducting the research, there was a meeting with the researcher and participants in order to get to know his students better and run a class without a TBLT approach before the pre-test of oral fluency assessment. Learners were expected to have a better oral fluency skill after having taught with the TBLT approach through classroom action research for about 16 hours over the 8 weeks of the classroom action research.

Data were obtained through IELTS speaking test format in order to measure learners' oral fluency skills. Since this is a classroom action research, there was a collaborator to observe the teacher's teaching and students' learning process. Collaborator was asked to give a comment on teaching and learning process during the classroom action period. Collaborator was provided with the teacher's lesson planning to provide a comment on the lesson, observation checklist, field note to observe during the teaching and learning process was going on. Moreover, some teaching videos were recorded in order to reflect on the learning and teaching process by the researcher himself and observe learners' interaction and talking time with their peers for oral fluency development during the learning process. Interview was also conducted so as to know learners' perceptions on their oral fluency on account of being exposed to a TBLT approach.

Data were analyzed Heaton formula (1990:9) in order to calculate the mean score of the test and interview was conducted only at the end of the research and interview questions were validated by the expert before conducting the research. Since this research employed classroom action research, there were some steps such as planning, acting, observation and reflection according to classroom action format (Kemmis and MccTaggart (1988). During the planning and acting stage, the researcher planned the lesson thoroughly according to the TBLT approach stages and applied in the classroom to discover learners' oral fluency development by involving and facilitating during the activities. With regard to observation and reflection stage, researcher was observed by the collaborator and provided some feedback and comment on learners' oral fluency skills during teaching and learning process through observation checklists and field notes.

There was an oral fluency test prior to the TBLT approach in order to know learners' current level of English proficiency. Learners' oral fluency skills were examined individually for about 15 minutes with the researcher and inter-rater who is a trained IELTS examiner so that learners were scored fairly and as accurately as possible. Speaking tests were audiorecorded so that researcher can listen twice for giving a score fairly. There were three tests to assess learners' oral fluency development namely, pre-test before conducting the research, cycle I after four weeks of teaching with TBLT approach, and cycle II after another four weeks of TBLT approach.

All of the data of statistical analysis was performed with STATA, version 14 (StataCorp LP: College Station, United States). Descriptive analyses consisted of the calculation of mean, range, the standard deviation for continuous variables, and frequency. Moreover, the Wilcoxon signed-rank test was used to compare the sum scores between pre-test vs cycle I, pretest vs cycle II, and cycle I and cycle II. A significance level was set at $<0.05$.

\section{RESULTS AND DISCUSSION}

This study was carried out in two cycles and as mentioned above, before carrying out this study, the preliminary test of oral fluency was examined so as to know learners' current oral fluency was held on 26th December 2020 in the format of IELTS speaking test but only focus on oral fluency criterion. IELTS official speaking criteria were employed with some adaptations in order to access oral fluency.

The results of the preliminary test were shown to present learners' current oral fluency before this research was carried out. The results of pre-test oral fluency were shown in Table 1.

According to the Table 1, it can be seen that only 3 out of 20 students were able to reach band 5.5 which indicates competent users of English according to the IELTS Test Report Form (TRF). According to the IELTS band indicators, band 9 is equivalent to the expert user of English whereas band 1 has no ability to use the language apart from a producing a few individual words[20]. The mean score of the pre-test was 3.825 and therefore, the majority of the students' oral fluency was considered to be limited users of English in general. 
Table 1. The preliminary Oral Fluency Test Results

\begin{tabular}{|c|c|c|}
\hline NO & STUDENTS' ID & SCORE \\
\hline 1 & $\mathrm{~A}$ & 4.5 \\
\hline 2 & $\mathrm{~B}$ & 4.5 \\
\hline 3 & $\mathrm{C}$ & 3.5 \\
\hline 4 & $\mathrm{D}$ & 3 \\
\hline 5 & $\mathrm{E}$ & 5.5 \\
\hline 6 & $\mathrm{~F}$ & 2.5 \\
\hline 7 & $\mathrm{G}$ & 5.5 \\
\hline 8 & $\mathrm{H}$ & 3 \\
\hline 9 & $\mathrm{I}$ & 3 \\
\hline 10 & $\mathrm{~J}$ & 3 \\
\hline 11 & $\mathrm{~K}$ & 2.5 \\
\hline 12 & $\mathrm{~L}$ & 4 \\
\hline 13 & $\mathrm{M}$ & 4 \\
\hline 14 & $\mathrm{~N}$ & 5.5 \\
\hline 15 & $\mathrm{O}$ & 5.5 \\
\hline 16 & $\mathrm{P}$ & 2.5 \\
\hline 17 & $\mathrm{Q}$ & 2.5 \\
\hline 18 & $\mathrm{R}$ & 5 \\
\hline 19 & $\mathrm{~S}$ & 4 \\
\hline 20 & $\mathrm{~T}$ & 3.825 \\
\hline & Mean score & \\
\hline & & \\
\hline
\end{tabular}

Graph 1 the IELTS band score descriptor from band 1 to 9

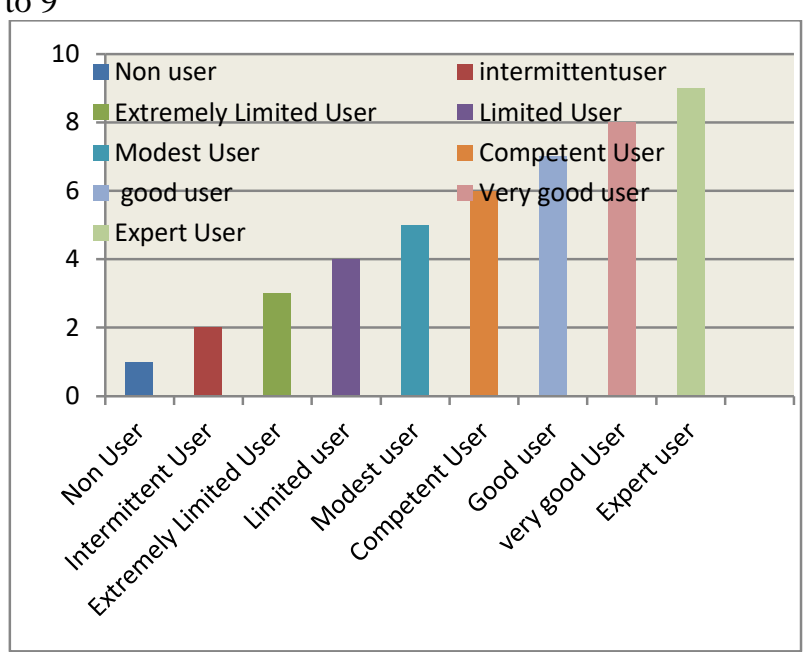

By looking at the graph and table above, in the preliminary test, there were only 3 out of 20 students were able to reach between modest users and competent users of English. There were 8 out of 20 students whose score between 2.5 and 3 which indicates extremely limited users of English. The rest of the students were between limited users and modest users. Due to a preliminary test results, it can be seen that learners' oral fluency skills were extremely limited in using English as the pre-test results of the mean score was 3.825 .
After conducting pre-test for oral fluency, the researcher started employing TBLT approach in order to enhance learners' oral fluency development for 8 weeks with a total of 16 teaching hours in the classroom.

According to the classroom action research procedure, the researcher planned the lesson thoroughly in order to make sure the lesson follows with the TBLT approach framework[10]. Moreover, there was a collaborator to observe the researcher's teaching and learners' learning process so that lesson plans follow according to the TBLT approach and collaborator was provided with the lesson plans, observation sheets and field notes for each meeting and therefore, researcher was given feedback and comment on his teaching and learners' learning process on their oral fluency development during the classroom action process. Moreover, some of the teachings were recorded for the purpose of the reflection on his teaching and to observe learners' interaction and participation during the lesson. The results of cycle I and cycle II can be seen in the following table.

Table 2. The results of Cycle I and Cycle II

\begin{tabular}{|c|c|c|c|}
\hline No & Students' ID & Cycle I & Cycle II \\
\hline 1 & A & 4.5 & 5.5 \\
\hline 2 & B & 4.5 & 4.5 \\
\hline 3 & C & 4 & 4.5 \\
\hline 4 & D & 3.5 & 4 \\
\hline 5 & E & 4.5 & 4.5 \\
\hline 6 & F & 5 & 5.5 \\
\hline 7 & G & 3 & 3 \\
\hline 8 & H & 6 & 6.5 \\
\hline 9 & I & 3.5 & 3.5 \\
\hline 10 & J & 3.5 & 3.5 \\
\hline 11 & K & 3.5 & 3.5 \\
\hline 12 & L & 3.5 & 3.5 \\
\hline 13 & M & 4.5 & 4.5 \\
\hline 14 & N & 4.5 & 5 \\
\hline 15 & O & 5.5 & 6 \\
\hline 16 & P & 5.5 & 6 \\
\hline 17 & Q & 3 & 3 \\
\hline 18 & R & 2.5 & 3 \\
\hline 19 & S & 5.5 & 5.5 \\
\hline 20 & T & 4.5 & 4.5 \\
\hline & Mean Score & 4.225 & 4.475 \\
\hline & & & \\
\hline
\end{tabular}

By looking at the results of Cycle I and II, the majority of learners' oral fluency seems to be improved even if it is not improved significantly. According to the IELTS criteria, even increasing half-band (.5) indicates that there is some improvement and therefore, the TBLT 
approach can be considered as an effective approach to the development of learners' oral fluency.

When we look at the mean score, 4.225 at cycle I which slightly increased to 4.475 at the end of cycle II and therefore, it indicates some improvements even if it is not a significant increase but at least some can be seen. For example, there is one student who was able to reach almost band 7 whereas two students were able to reach band 6 and therefore, the researcher was quite satisfied by seeing some improvements. Some of the students were eventually able to reach band 3 and therefore by comparing the results of a cycle I and II, some have remained the same but there was an improvement between pre-test and cycle I which can be seen in the following table from pre-test to cycle II results.

Table 3. Comparison among Pre-Test, Cycle I and Cycle II

\begin{tabular}{|c|c|c|c|c|}
\hline No & $\begin{array}{c}\text { Students' } \\
\text { ID }\end{array}$ & Pre-Test & Cycle I & $\begin{array}{c}\text { Cycle } \\
\text { II }\end{array}$ \\
\hline 1 & A & 4.5 & 4.5 & 5.5 \\
\hline 2 & B & 4 & 4.5 & 4.5 \\
\hline 3 & C & 3.5 & 4 & 4.5 \\
\hline 4 & D & 3 & 3.5 & 4 \\
\hline 5 & E & 4 & 4.5 & 4.5 \\
\hline 6 & F & 5 & 5 & 5.5 \\
\hline 7 & G & 2.5 & 3 & 3 \\
\hline 8 & H & 5.5 & 6 & 6.5 \\
\hline 9 & I & 3 & 3.5 & 3.5 \\
\hline 10 & J & 3 & 3.5 & 3.5 \\
\hline 11 & K & 3 & 3.5 & 3.5 \\
\hline 12 & L & 2.5 & 3.5 & 3.5 \\
\hline 13 & M & 4 & 4.5 & 4.5 \\
\hline 14 & N & 4 & 4.5 & 5 \\
\hline 15 & O & 5.5 & 5.5 & 6 \\
\hline 16 & P & 5.5 & 5.5 & 6 \\
\hline 17 & Q & 2.5 & 3 & 3 \\
\hline 18 & R & 2.5 & 2.5 & 3 \\
\hline 19 & S & 5 & 5.5 & 5.5 \\
\hline 20 & T & 4 & 4.5 & 4.5 \\
\hline & Mean Score & 3.825 & 4.225 & 4.475 \\
\hline & & & & \\
\hline
\end{tabular}

The following graph demonstrates the mean scores of the learners' oral fluency development based on IELTS speaking test format and criteria with some adaptations.
Graph 2 Mean Scores from Pre-Test to Cycle II

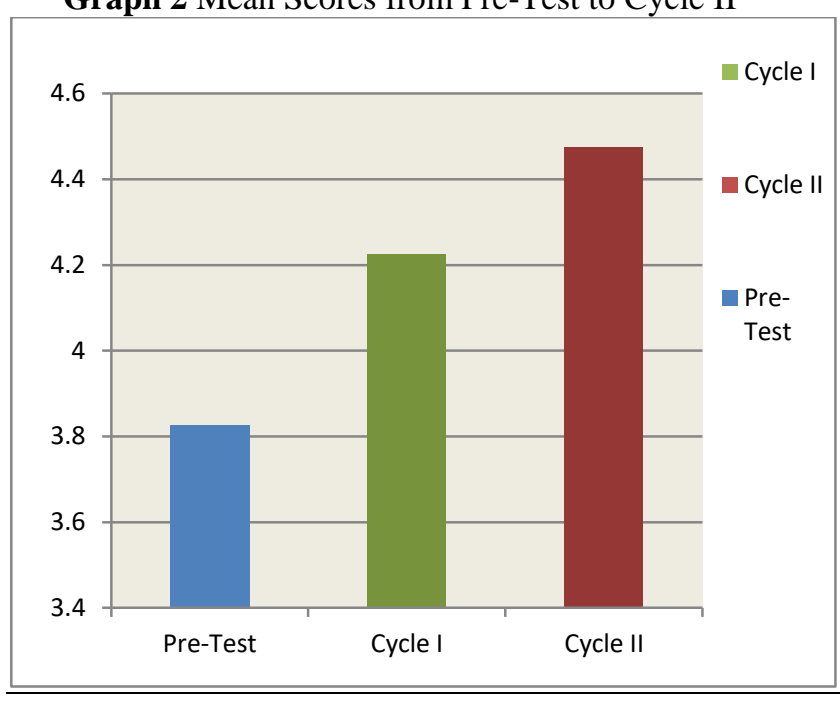

Having provided the mean scores and tables above, it can be seen that at the end of research cycle II, one student was almost able to reach band 7 which is equivalent to the good user whereas 2 students were able to reach band 6 which is equivalent to competent users and 3 students were able to reach band 5.5. Most of them were scored band 5, 4.5,4 and 3.5 respectively whereas only 3 of them were scored band 3 at the end of the research. According to the Heaton formula for the mean score of the oral fluency test, it increased steadily from 3.825 to 4.474 at the end of cycle II. It can be concluded that learners' oral fluency was steadily increased through the TBLT approach.

Moreover, when we measure the sum score of the oral fluency test through with Wilcoxon sign-rank test, the sum-score of the test from pre-test to cycle II was found different, and therefore, it can be said that oral fluency was developed from each cycle.

The sum scores can be seen as follows:

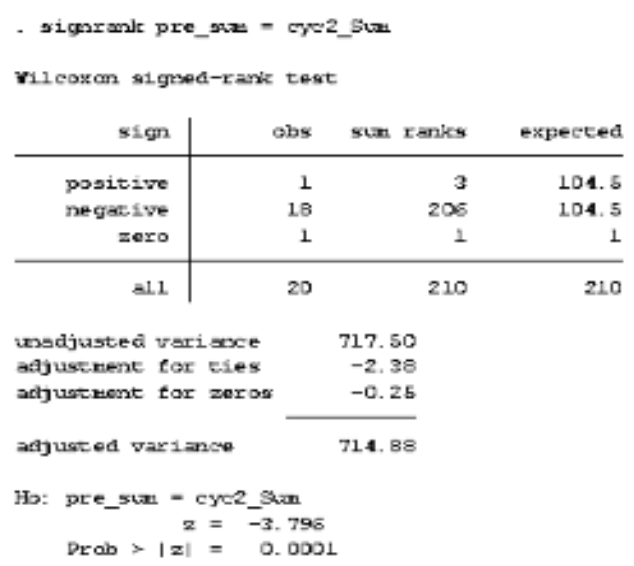


Since the p-value is $0.0001<0.05$, therefore, the sum score of the pre-test and cycle II is different, and can be concluded learners' oral fluency was enhanced through the TBLT approach.

Based on the results mentioned above, there is some improvement in the aspect of learners' oral fluency but not significantly due to the limited time of the research period. To begin with, at the preliminary test, the average score of the learners' oral proficiency was just above band 3 which is an extremely limited user according to the IELTS band descriptors. Due to the pre-test results, the researcher was convinced that learners have a problem in relation to their oral fluency despite having some grammatical knowledge and started helping learners' oral development through the TBLT approach with the classroom action research procedure.

After four weeks of being exposed to the TBLT approach, learners' oral development was slightly increased with the calculation of Heaton's (1990:9) formula of mean score from 3.825 to 4.225 and Wilcoxon signed-rank test sum score of the p-value is $0.003<0.05$. By looking at this statistical analysis, the pre-test score and cycle I test were different and therefore there is some improvement of learners' oral fluency. After cycle I, there was another four weeks of teaching the TBLT approach to enhance learners' oral fluency. After eight weeks of being taught with the TBLT approach, learners' oral fluency test score was increased slightly again compared to the cycle I with almost band 1 increase can be seen. For instance, regarding the mean score, 3.825 to 4.475 , and the sum score of Wilcoxon signed-rank test of p-value was from 0.0001 which is less than 0.05 and therefore, the researcher decided to stop because improvement can be seen after each cycle.

Therefore, the TBLT approach is one of the effective ways to enhance learners' oral fluency as this research had proved the effectiveness of TBLT approach. However, some misconceptions about the TBLT is not suitable for exam preparation classes, in fact, TBLT approach can design for the exam classes [11][10] in particular exams which test for the authentic language use and learners' communicative ability such as IELTS speaking test, for instance.

During the action in the classroom, students needed a lot of scaffolding at the beginning of the lesson as an input language due to the fact that some students were unable to convey the basic instruction of the language and confused about what to do due to a language barrier according to the collaborator's comment on field notes. In fact, the researcher checked the instruction and concept check for the vocabulary but some students were unable to convey the basic message and unable to express it in English. Therefore, researcher did a lot of scaffolding process during the entire cycle I process at the pre-task stage so that learners were equipped the language and were able to discuss in pairs and group works with little assistance with the teachers but learners had a lot of conversation through helping each other which is the signal of the learners' involvement and could stimulate their interests and ultimately develop their oral fluency.

After cycle I, learners did not need much scaffolding process as they were more accustomed to the researcher's language use and instructions, and more interactions were seen compared to the previous meetings during the learning process. As the researcher usually starts a repetition task which can enhance learners' oral fluency before starting the lesson and activate their prior knowledge of the lesson as well as recalled the previous lesson as the results, learners' oral fluency were improved slightly after cycle II. As it is said[22] that task repetition can provide learners' oral performance at least temporarily and therefore, researcher usually starts repetition tasks at the pre-task stage such as previous lesson and as task repetition include asking learners to repeat the same things or slightly differences such as changing partners but the same task[23].

Having said that since the learners' oral fluency was not dramatically improved in this study due to the fact that first, the research period was limited, and second, learners' did not have many opportunities to use outside of the class. In order to answer the research question of this study, learners' oral fluency was improved slightly, indeed through classroom action research with the TBLT approach. In other words, before conducting the research, learners' oral fluency was extremely limited and therefore, the researcher met one meeting before approaching the TBLT approach so as to get to know his students and their interests along the way of the research period. After identifying learners' problems and knowing their interests, the researcher planned the lesson plans accordingly to be able to engage with his learners and stimulate their interests. As the researcher collected information through observation sheets and field notes from the collaborator as well as watching the recorded videos of teaching and researcher was able to reflect on his own teaching of strengths and weaknesses for the further improvement of the next meetings and particularly, it was interesting to see that task repetition and scaffolding were the fundamental of pre-task stage of TBLT approach. In fact, the effects of task repetition on the oral skills research have been conducted in a several studies and discovered that it has a positive effect on oral production[23] and therefore, it plays a crucial role in the approaching of TBLT in language classroom. 
After all, the researcher could summarize that learners require a lot of scaffolding at the input stage in particular if the learners are beginner and elementary levels or mixed-ability classes. In fact, during the scaffolding, the role of a teacher is activating learners' prior knowledge as well as providing language input in relation to the topics so that learners will be able to discuss the tasks more effectively without having much support from their teacher. Moreover, according to the interview, some students expressed their opinion of being taught TBLT was quite satisfying and have plenty of time to practice the English language during the class activities. Most of them expressed that the TBLT approach was the first time in their lives being taught and therefore, they wish the TBLT approach should have been taught in their junior or senior high school so that they would have been a better fluent speaker now. One student even mentioned during the interview that after being taught with TBLT approach, he even used some English words unconsciously during the conversation with his friends and which can indicate a better fluency skill, to say the least.

Last but not least, TBLT approach is also suitable for exam preparation such as IELTS as this study employed IELTS speaking test format to access learners' oral fluency, and therefore, if only time is allowed, the IELTS preparation exam can be done through the TBLT approach. However, it is important to keep in mind that task-repetition and scaffolding are the integral part of the pre-task stage of the TBLT approach.

\section{CONCLUSION}

A task-based approach is explicitly designed for learners to be able to communicate effectively in which learners are actively engaged with meaning focus[17]. Therefore, this research study was aiming for developing learners' oral fluency skills through classroom action research and the results proved that TBLT, in fact, helps learners' oral fluency development provided that learners are facilitated through task repetition and scaffolding at the pre-task stage of the TBLT framework [10] as a language input in particular at the teaching of beginner or elementary level so that learners will be able to perform at the task-cycle stage.

According to the observation notes and field notes comment on the TBLT approach, learners were given plenty of time to interact with their peers and as a result, enhance their oral fluency skills. Moreover, the researcher was able to reflect on his teachings video which tremendously caters to learners' learning process more effectively. Therefore, reflective practice plays a pivotal role in the action research as well as for those who would like to enhance their professional development. As it has mentioned before, TBLT is suitable for all learners of English and can simply apply for exam preparation but it is critically important to adapt and adopt depends on the learners and cultural background of the students. Students require guiding at the initial stage of the speaking task such as pre-task stage in order to perform well when it comes to initiating the conversation in groups or pairs[24]. Moreover, as Maybin, Mercer \& Steirer (1992) said "Scaffolding activities bring learners closer to a state where they can eventually do the task well without teachers' help". Therefore, scaffolding is the crucial element to enable learners to accomplish the task on their own[25] in the approach of TBLT.

\section{REFERENCES}

[1] Y. Ji, "Task-based Language Teaching ( TBLT ) in Asian EFL classes : Challenges and Strategies," vol. 120, no. Mshsd 2017, pp. 152 164, 2018.

[2] Y. G. Butler, "The Implementation of Communicative and Task-Based Language Teaching in the Asia-Pacific Region," Annu. Rev. ofApplied Linguist., vol. 31, no. 1, pp. 36-57, 2011, doi: 10.1017/S0267190511000122.

[3] W. Littlewood, H. Kong, and W. Littlewood, "Plenary speeches Communicative and taskbased language teaching in East," pp. 243-249, 2018, doi: 10.1017/S0261444807004363.

[4] A. Aziz, I. Agama, I. Negeri, and I. Bengkulu, "The effect of task-based language teaching (tblt) strategy on students' speaking ability in demonstrative speech Abdul Aziz Institut Agama Islam Negeri (IAIN) Bengkulu," J. Linguist. Lang. Teach., vol. 4, no. 2, p. 20, 2018.

[5] M. East, "Thinking Allowed Research into practice : The task-based approach to instructed," no. 2017, pp. 412-424, 2021, doi: 10.1017/S026144481700009X.

[6] J. Harris, "Responding to the critics : Implementation of TBLT in Japan," vol. 8, no. 1, pp. 139-148, 2018, doi: 10.17509/ijal.v8i1.11473.

[7] D. Nunan, Task-Based Language Teaching, First Edic. Cambrige University Press, 2005.

[8] A. Dailey, "Implementing Task-Based Language Teaching in Korean Classrooms Module 1 Assessment Task," Univ. Birmingham, no. July, pp. 1-20, 2009.

[9] V. S. Pavel, "TBLT in practice: The task-based language teaching approach," 2013.

[10] J. Willis, "Jane Willis - A Framework for TaskBased Learning (Longman Handbooks for Language Teachers)-Addison Wesley Publishing Company (1996).pdf.” Longman, p. 179, 1996. 
[11] D. Willis and J. Willis, Doing Task-Based Teaching. NEW YORK: Oxford University Press, 2007.

[12] H. Y. Phuong, "Challenges of shifting to taskbased language teaching: A story from a Vietnamese teacher challenges of shifting to task-based language teaching : a," Can Tho Univ. J. Sci., vol. 2, no. January 2016, pp. 37-45, 2017, doi: 10.22144/ctu.2016.jen.002.

[13] D. Carless, "Revisting the TBLT versus P-P-P debate : Voices from Hong Kong," Asian J. English Lang. Teach., vol. 19, pp. 49-66, 2009.

[14] D. Carless, "The suitability of task-based approaches for secondary schools : Perspectives from Hong Kong," doi: 10.1016/j.system.2007.09.003.

[15] R. Ellis, "Task-based language teaching : sorting out the misunderstandings," Int. J. Appl. Linguist., vol. 19, no. 3, 2009.

[16] R. Adams and J. Newton, "TBLT in Asia: Constraints and opportunities," Asian J. English Lang. Teach., vol. 19, pp. 1-16, 2009.

[17] J. Willis, "Task-based language teaching : Some questions and answers," Journal, pp. 3-8, 2009.

[18] N. Segalowitz, Cognitive Bases of Second Language Fluency. Routledge, 2010.

[19] Scott Thornbury, "Scott Thornbury - How to
Teach Speaking-Longman (2005).pdf." Longman, p. 155, 2005.

[20] T. Speaking and B. Descriptors, "Assessing Speaking Performance IELTS Examiners and speaking assessment in the IELTS exam Speaking performances are assessed by certificated IELTS examiners . All IELTS examiners hold relevant teaching qualifications and are recruited as examiners by the t," UCLES, Cambridge Universtity Press, pp. 1-12, 2011.

[21] C. Dore, Perceptions of Fluency Author' s Name : Cecilia Dore University of Reading, Thesis Dis. University of Reading, 2016.

[22] J. Fukuta, Effects of Task Repetition on Learners 'Attention Orientation in L2 Oral Production, no. July. 2018.

[23] M. J. Ahmadian, "Task repetition in ELT," ELT Journal, Oxford Univ. Press, vol. 66, no. 3, pp. 1-3, 2012, doi: 10.1093/elt/ccs020.

[24] C. C.M.Goh, "Research into practice : Scaffolding learning processes to improve speaking performance," Lang. Teach., vol. 50, no. 2, pp. 247-260, 2017.

[25] J. Maybin, N. Mercer, and B. Stierer, "Reading 7 ' Scaffolding' learning in the classroom," Think. voices, 1992. 